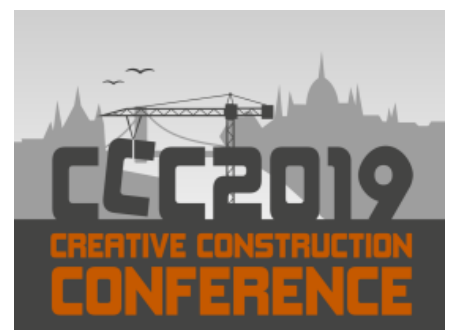

Available online at 2019.creative-construction-conference.com/proceedings/

CCC 2019

Proceedings of the Creative Construction Conference (2019) 061

Edited by: Miroslaw J. Skibniewski \& Miklos Hajdu

https://doi.org/10.3311/CCC2019-061

Creative Construction Conference 2019, CCC 2019, 29 June - 2 July 2019, Budapest, Hungary

\title{
SYSTEM ADJUSTMENTS THROUGH VECTOR ORGANIZATION AND TECHNOLOGY
}

\author{
VLADIMIR KRIŽAIĆ \\ Polytechnic of Međimurje in Čakovec, Čakovec 40000, Croatia
}

\begin{abstract}
The production system is in the function of the organization and the technology of an implied system. The organization is the function of the structure and the flow, which in turn defines the unity of the arranged interrelated elements. The use of new technologies, especially the ones from the realms of computer science and cybernetics, and integrating them into the building industry technologies provides for enhancing the building industry business flow indices. The existing organization structure is thus to be supplemented with adjustment tool which is inevitable for systems and provides for business systems to feature the resources/days -based levels of control over projects. IIS technology has thus turned the matrix organization structure of the building industry into the vector one.

The discrete norm elements should be replaced by the vector norm elements for the purpose of speeding up the technologic processes of planning and norm defining that are in turn the motors of companies providing for the deployment of he implied controls (system adjustment, that is); in other words, it means that the BIM business system - or the whole system as well- should be modeled. By means of further modeling and the BIM system simulations, there emerges the building industry business DSP model within the micro unit. The DSP method (dynamic structured programming) ) integrates the dynamic and the structu8red programming and provides - for the time being.-for a dynamic modeling of structures and the flow through the formula within the vector system; as to the future, it will provide for defining the organization differential by means of iterating multidimensional model structure.
\end{abstract}

(C) 2019 The Authors. Published by Budapest University of Technology and Economics \& Diamond Congress Ltd.

Peer-review under responsibility of the scientific committee of the Creative Construction Conference 2019.

Keywords: vector organization; vector norm; daily system adjustments; BIM and DSP models;organization differential

*vladimir.krizaic@gmail.com

This paper describes the results of research being carried out within the project "Centar održivog razvoja"/"Center of sustainable development", co-financed by the European regional development fund and implemented within Operational Programme Competitiveness and Cohesion 2014 2020, based on the call "Investing in Organizational Reform and Infrastructure in the Research, Development and Innovation Sector". 
Vladimir Križaić / Proceedings of the Creative Construction Conference (2019) 061

https://doi.org/10.3311/CCC2019-061

\section{Introduction}

Each system is a structural unit of single elements and the flow through these elements which, in turn, defines the unity of ordered interrelated parts, i.e. the elements of the system. In the building industry production business system that is so important to us, organization and technology interweave as the two key subsystems that make up the structure and the flow of all the components of the implementation of building industry projects [1]. The already existing subsystems were being created in the course of history and within their specific structures with some of them still giving good business results in some economy and politics systems; however, the production systems aiming at better business indices require a further development of organizational and technological structures. The matrix business structure is considered today to be the most suitable one for building industry. The system control we have known up to now is in turn supplemented with adjustment tool that is inevitable in the contemporary era of cybernetic control [2]. The use of these technologies, especially the ICT and cybernetic ones, and implementing them into the building industry technology provide for upgrading of building industry business results indices and for the defining of the adjustment tool at the level of resources and days, i.e. at the level of the organizational differential. Such daily-based system adjustment provides for IT defining of planning the projects and for reducing risk within projects. [3].

\section{Modeling and Adjustments of the System}

Modelling and simulation of systems are extremely popular nowadays, especially via $3 \mathrm{D}$ and $\mathrm{nD}$ as well as via linking systems into BIM systems [4]. The purpose of BIM is handling the information at any time, i.e. the unique information related to a particular day and emerging from a unique integrated information system and from each branch of activities related to the project. By means of mere classic transfer of data from old models into the information system, no advance in business results can be achieved. It also proved to be insufficient if static models are copied into information systems and thus the key problem of the $4^{\text {th }}$ industrial revolution was defined as well. Computers are intended for processing based on cyclic and variable qualities of data mass through functional (algebraic) presentation. This is why the organization and technology of all systems - including the building industry ones- have to be standardized/modeled by means of dynamic $\mathrm{nD}$ models in the function of project documentation variables [5]. These models, defined mathematically and in accordance with their algorithmic qualities, will gain positive effects regarding the principles of doing business and the quality of all processes of being administratively accessible. The transfer of the old technology for defining expense list and creating the respective offer into the software system based on the old organizational and technological structures also proved efficient only to a very moderate extent, i.e. it was an obstacle for the development of the whole economy branch. The features of the old static system of norms are linearity, discreteness and a lack of standard of describing the norm process. The description of a process is thus never complete despite comprising initially more than 20000 words, 100000 records and 7000 resources. So, the key problem is the static, discrete norm defined through a mere "parts list" and extremely fixed and inflexible in terms of variability of the project resources dimensions, especially when the new technologies are implied. However, for the purpose of speeding up the technological planning and norm-setting processes for the development "engines" of a company that in turn lead to certain control (modeling) of a system, the discrete norm elements have to be replaced by the dynamic ones. These elements can be model-standardized and optimized, which leads to achieving the goals being set by any business system including the building industry ones as well. Yet, however, the static copying of data teamed with IT indicated a new component of the organization system, namely resource.

\section{3D Vector - Organizational System Structure}

The assumption is that the static PBO (project of building organization) should be replaced by a dynamic one, i.e. by model standardization [6] of the building and all other industries by means of deploying 3D organization and $\mathrm{nD}$ technology. In that way, the information processing system checks a source as a component and presents the quicklyaccessible information as the third component of the organization structure; thus the vector organization structure of the company is created and this is in fact the 3D organization structure. Considering the current development of various business organization structures in the building industry, the mostly preferred one is the matrix organization with a stress on the project implied, a project-oriented organization in other words. Such a financial monitoring system proved to be insufficient for an effective monitoring of the productivity indices, so the structure is supplemented with processmonitoring of projects in order for the obstacles for project implementation are detected as soon as possible. IS - 
integrated information system of the building industry executi provides for monitoring of a project down to the level of resource. Thus, the resource axis is added to the matrix axis as the third spatial (vector) structure - Fig 1
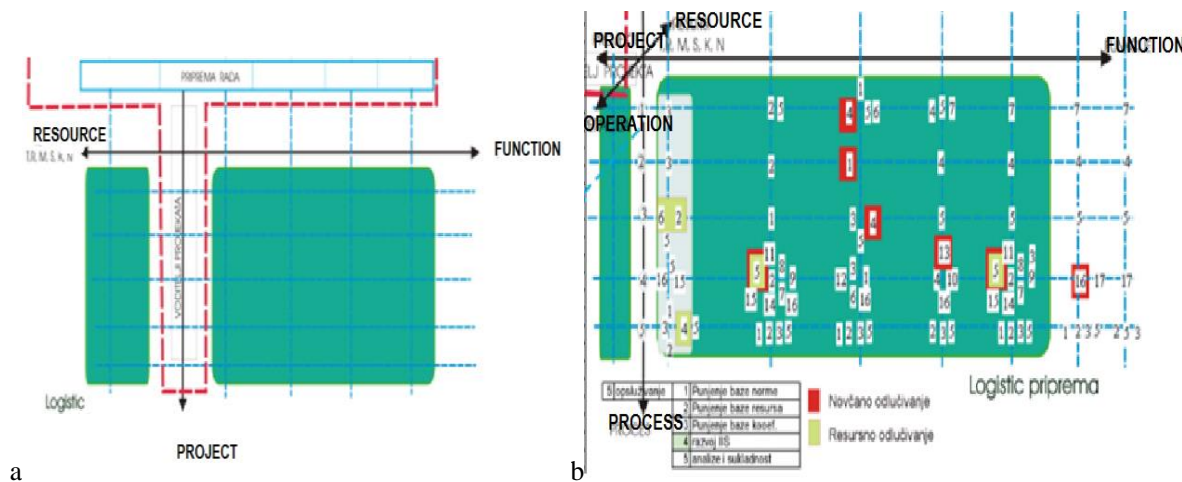

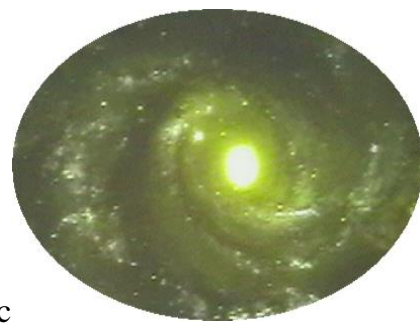

Fig. 1. (a) vector-matrix structure, (b) vector-matrix structure oriented to resources (c) The Universe - Cycle-vector

A further gradual branching of the system from processes to operations, procedures and increments in a coordinate presentation gives an $\mathrm{n}$-dimensional system, i.e. a vector presentation of organization or a building industry system in the work-out of the PBO (project of building organization). By means of breaking down (deduction) of the procedures within the work preparation procedures in envisaging $\mathrm{PBO}$ as a logistic function of production, the products of a certain procedure are defined graphically or analytically and they are as well presented in the vector PBO system. These results of PBO are offer, gantogram, histogram, S-curve etc. Fig. 2.
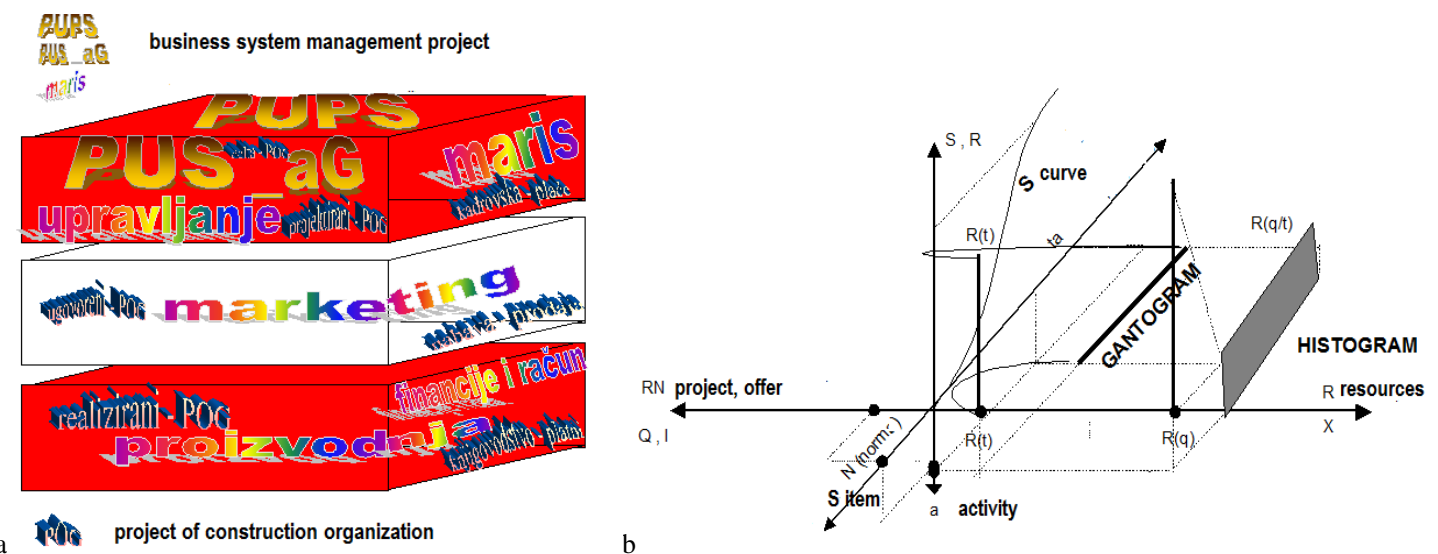

Fig. 2. (a) BIM- IIS PUPS, (b) Vector presentation of work results - PBO

\section{4D , nD - Vector Production System Technology}

Similarly, the 4D norm model or vector norm developed from the static norm. Materials and permanent assets are in the function of the constructive and geometric properties of a building industry project within the given technology framework, so the consumption of materials is boiled down to the project documentation dimension by means of relating the constructional equations to the resource efficiency. The results of the relating represent the monograms of the bearing capacity of buildings that at the same time serve as resource norm for the given building. The tendency to make the monitoring of resource shorter and faster created the vector presentation of norm, the vector MSN [7] in other words. The creation of norms in accordance with workers' vocations reduces the quantity of work norm discrete data whereas the model is obtained by defining the functional relation of norm resources and time with the dimension of a building or works. The time norm can be presented as the resource efficiency in the three-dimensional equation. The variables are the elements of technology $Y_{r}$, organization $Z_{o}$ and project construction $X_{k}$ as shown in Fig. 3 . 

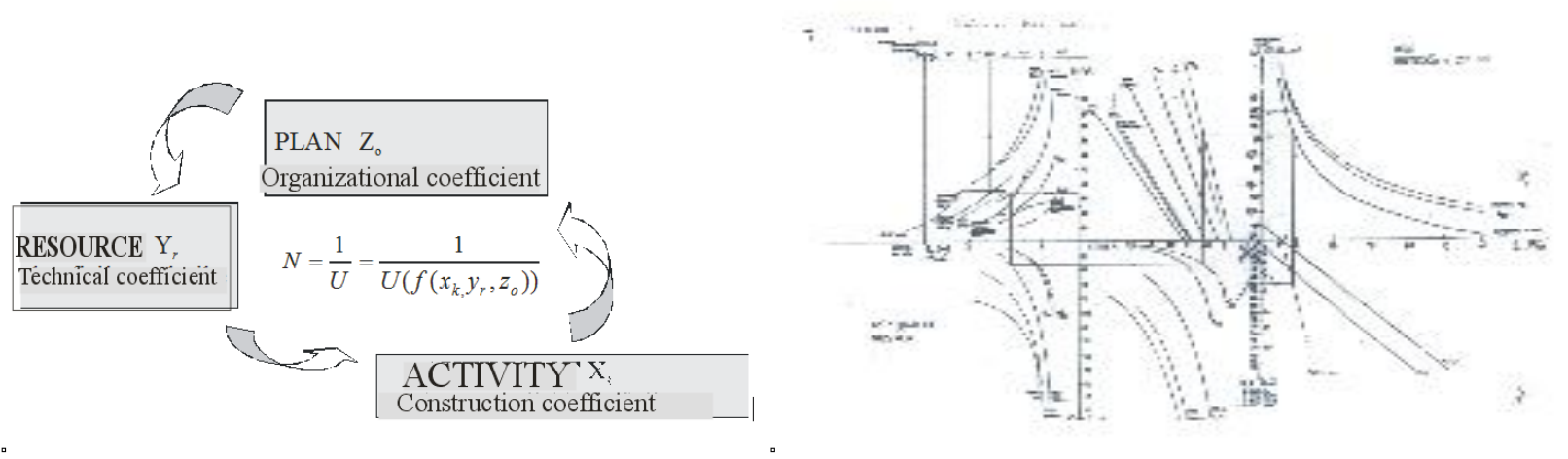

Fig. 3. (a) Vector norm model, (b) vector monogram for concrete formworks technology-Construction Works Company GK Međimurje

The analysis and systematization of the old norms have brought the three-dimensional variables into sight, namely the variables of construction, technology and organization for the purpose of defining the vector norm hypothesis [8] (1, 2).

Vektorski_normativ $=N_{k, r, k o_{k}, k d_{i}}=k d_{i}\left(k o_{k}\left(f_{0}(k, r)\right)\right)$

Based on examples of various technologies, the tables were created in the function of the constructive elements of performance $(k)$ and the dimension of that performance element $\left(k d_{i}\right)$ as well as of resource $(r)$ which means the performance technology and of organization with defining the basic type of the constructive element $\left(k o_{k}\right)$ representing an organization unit. By means of using these variables, all the static tabular presentations of various systems can be boiled down to the graphic vector presentation. By extracting the constructive element, which is the easiest to define and is thus most frequently used, the basic constructive element is defined $(k)$ in dependence of which other construction elements are written down at the given $\left(k o_{k}\right)$. For the purpose of defining the equation for the minimal time-span of the basic constructive element for the discrete values mass given, Gauss least median of squares method is the most feasible as it gives approximations, i.e. it gives the model norm for the basic system. Materials and permanent assets are in the function of the constructive and geometric properties of a building industry project within the given technology framework, so the consumption of materials is, by means of relating constructional equations to the resource effectiveness, boiled down to the project documentation dimension. The results of the relating represent the monograms of the bearing capacity of buildings that at the same time serve as the resource norm for the given building.

$$
\text { Vektorski_normativ }=N_{k, r, k o_{k}, k d_{i}}=k d_{i}\left(k o_{k}\left(f_{0}(k, r)\right)\right)=\sum_{k d_{i}} k d_{i}\left(\sum_{k o_{k}} k o_{k}\left(\sum_{k} \sum_{r} f_{o}(k, r)\right)\right.
$$
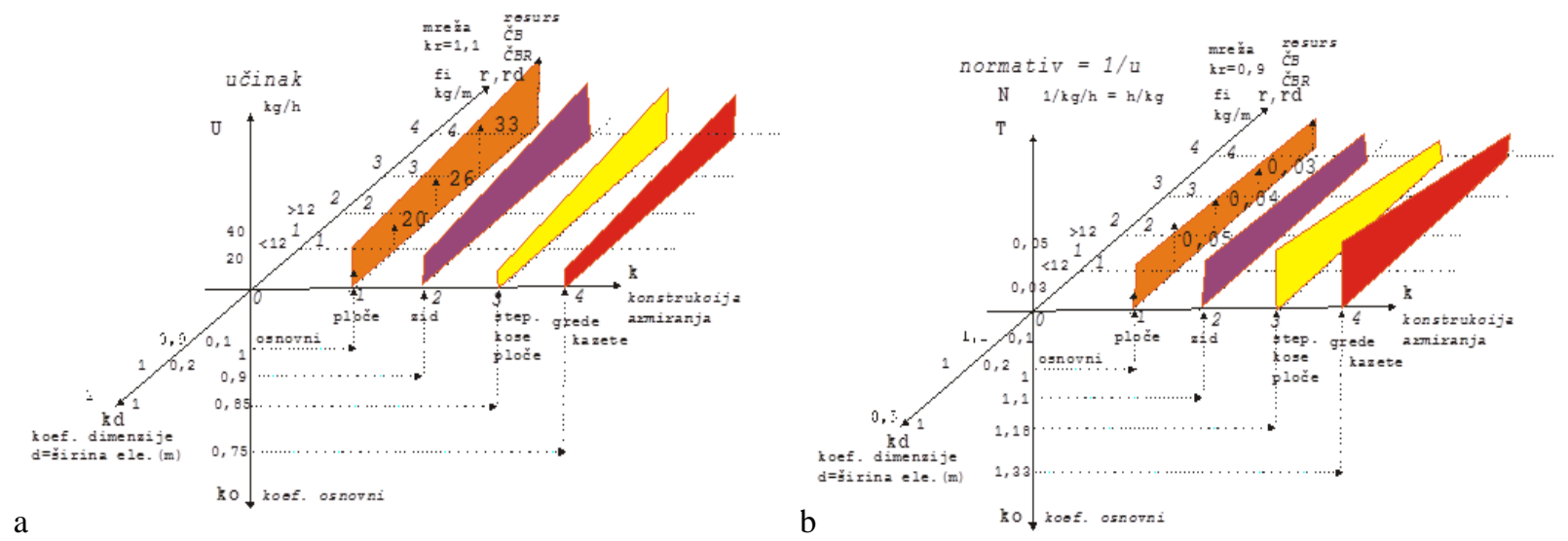

Fig. 4. (a) concrete reinforcing efficiency, (b) concrete reinforcing norm 
Vladimir Križaić / Proceedings of the Creative Construction Conference (2019) 061 https://doi.org/10.3311/CCC2019-061

\section{Model Standardization of nD and DSP BIM System Technologies}

The linking and updating of the afore mentioned models by the iteration software technology lead to the development of DSP model that was supported by model solving of the problems related to defining production and products based on operational research [9]. The product is thus PBO and the offer is defined as $\mathrm{P}=\Sigma \mathrm{F}_{\mathrm{n}}\left(S_{i, j}\right)=\mathrm{f}(\mathrm{T}, \mathrm{O})$, a function of technology (construction) record and the performance technology, whereas $\mathrm{T} \approx \mathrm{O}=\mathrm{f}(\mathrm{A}, \mathrm{R}, \mathrm{D})$, i.e. as the function of variables A-activities, R-resources and $\mathrm{D}$ - the dimension of construction and the performance resources efficiency. The problem of the product "parts list" is solved by vector defining of structures in the dynamic programming manner, where computers appear feasible for this aspect of two- and more- dimensional operations.
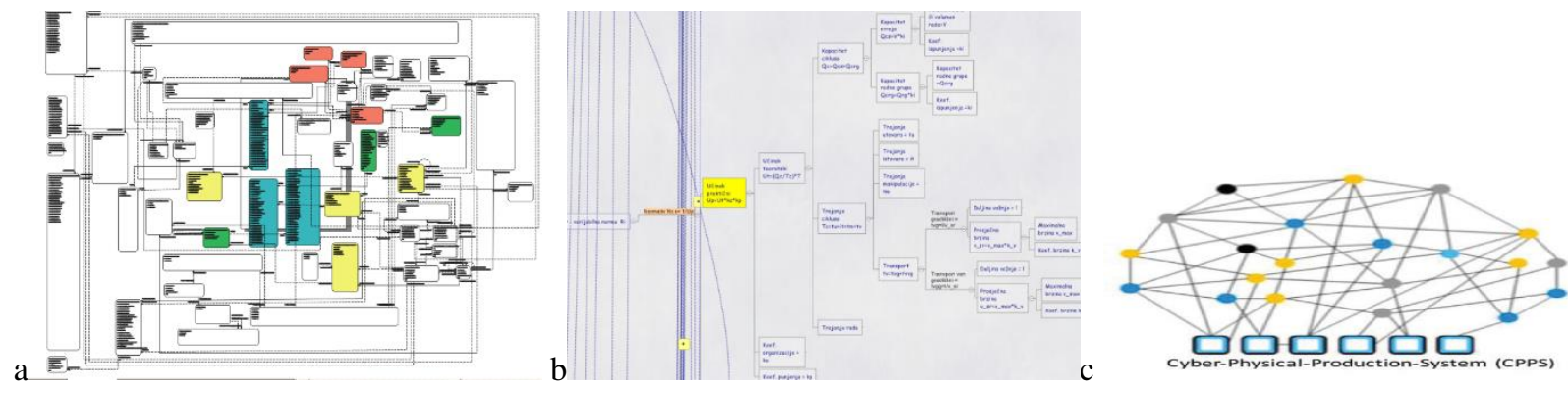

Fig. 5. (a) modeling entity for a computer (nD) (b) modeling of data by MindManager - DSP method (c) Cyber system [10]

This aspect of the technologic achievements dissolving into organizational ones for the purpose of relieving the gap among them results in designing the cyber- physical-productive system model $[10,11]$ with the respective presentation in MindManager [12]. VNS - vector norm standardization fits as well into DSP model when the vector or variable norm model is included in the organization matrix and dimension submatrix (3).

$\left[T_{n}\left[O_{n}[k e, j m, k, c, v]_{n}\right]\right]=\left[T_{n+1}\left[O_{n+1}[k e, j m, k, c, v]\right]\right]$

A further simulation of the afore mentioned models by means of the cybernetic Cro-Podturen equation [13] provides for describing various states of the system (4).

$\left.K=U\left[\begin{array}{c}n_{1} \rightarrow k_{\max }-1 \\ n_{\max } \downarrow\end{array}\right]\left[\begin{array}{l}n_{2} \rightarrow 1 \\ n_{1}-k_{i} \downarrow\end{array}\left[\begin{array}{c}\left.n_{i} \rightarrow n_{i}+1\right\lrcorner n_{k}-1 \\ n_{1}-k_{i} \downarrow\end{array}\left[\begin{array}{c}n_{k} \rightarrow n_{1}+1 \\ n_{\max } \downarrow\end{array}\right]\right]\right]\right]$

The deployment of system elements state probability in the given model leads to Markov and DSP stochastic models that can define a project based on time and expenses and the variables define the risk level for the project. Modified Gauss equation (5) is a prototype for the real S-curve in the function of $\mathrm{T}$ and $\mathrm{x}$ or $\mathrm{t}$. For that purpose, more data from the field are required, the suggested linear models should be studied and coefficients $(a, b)$ have to be defined with a highest possible level of preciseness and probability (5) Fig.6.

$$
\begin{aligned}
& \operatorname{skv} G(x, T)=\lambda k v * \int_{0}^{x} \frac{1}{(a T+b) * \sqrt{2 \pi}} * e^{\frac{-(x-\mu)^{2}}{k v *(a T+b)}} d x \\
& \text { (1) }
\end{aligned}
$$

Fig. 6. Modified Gauss curve on existence of a project in time and expenses variables 
Vladimir Križaić / Proceedings of the Creative Construction Conference (2019) 061

https://doi.org/10.3311/CCC2019-061

\section{Conclusion}

The response to the problem of informatizing of building industry production is the deployment of model production standardization. Mathematical modeling or vector modeling creates $n$-dimensional modeling of various processes. In line with shaping the constructors' physical phenomena mathematically, modeling (mathematicising) of business systems as organizational components is more and more common today. A further cyberneticizing and softwarizing of the organizational cybernetic models create models that are easy for computers to process, This has given a new momentum to the research in the risk of doing business field thus defining the probability of processes taking place through defining uncertainty or consequences. This aspect of the technologic achievements dissolving into organizational ones for the purpose of relieving the gap among them results in designing the cyber- physical-productive system model. The objective of the modeling and standardizing method is to define the processes of building industry products as accurately and precisely as possible. The intentions of the building industry are modeling of project implementation "just in time" and adjusting the production system and the business system as a whole in a way that provides for monitoring and controlling a project on daily basis, i.e. daily monitoring. DSP method of updating through the cybernetic and combinatory approach may as well change the classic operative research scientific branch and it is thus recommended that new state and EU interest norm projects should be started concerning the detection and defining of the development of standardizing technologies and organizations. Defining these models means a lot of ceaseless work that requires upgrading the states of science and economy. The final result is to spur on new discoveries in the fields of developing standards of technologies and organizations, relieving the gap among them through so-called software mathematics and stipulating an increased level of utilizing BIM principles in processes of business operations.

\section{References}

[1] Rudolf Lončarić (1995): Organizacija izvedbe graditeljskih projekata, HDGI - Zagreb

[2] Marko Žaja (1988): Kibernetika i opća teorija sistema, GIZ -Zagreb

[3] Ivo Andrijanić,Miroslav Gregurek, Zvonko Merkaš (2016): Upravljanje poslovnim rizicima, Liberta-Plejada, Zagreb

[4] Abanda, F.H. Kamsu-Foguem, B. : BIM - New rules of measurement ontology for construction cost estimation, Oxford Institute for Sustainable Development, School of the Built Environment, Faculty of Technology, Design and Environment, UK

[5] Vladimir Križaić (1991): CALCULATION OF TEMPORARY STRUCTURES carpentry reduced to DIMENSIONS OF PROJECT DOCUMENTS, Dubrovnik

[6] Vladimir Križaić (1996): MODEL STANDARDIZATION, VI. Internacional symposium «BUILDING ECONOMICS» Zagreb

[7] Vladimir Križaić (2002): MODEL STANDARDIZATION II - The Ninth International Conference on computing in Civil and Building Engineering, Taipei, Taiwan

[8] Vladimir Križaić (2014): Application of Norms Models with Vectoral System in Construkction Projects, JOURNAL OF Civil Engineering an Architecture, USA, ISBN 1934-7359 str. 722-728

[9] Jovan Petrić (1987): Operaciona istraživanja, Naučna knjiga Beograd

[10] Santiago Ruiz-Arenas, Imre Horváth, Ricardo Mejía-Gutiérrez, Eliab Z. Opiyo Delft University of Technology, Faculty of Industrial Design Engineering, the Netherlands Universidad EAFIT, Design Engineering Research Group, Colombia: Towards the Maintenance Principles of Cyber-Physical Systems

[11] Clemens Fallera, Max Höftmanna: Service-oriented communication model for cyber-physical-production-systems

[12] https://www.mindjet.com/

[13] Vladimir Križaić, Dražen Hranj, Tibor Rodriger (2018): UTJECAJ SOFTVERSKE MATEMATIKE NA MODELIRANJE U GRADITELJSTVU 5. međunarodna konferencija INOVACIJE, TEHNOLOGIJE, EDUKACIJA I MENADŽMENT 4. i 5. travnja 2018., Sveti Martin na Muri, Croatia 